\title{
Geospatial Dimension of Public Health: Public Ownerships, Private Operations, and Individual Responsibilities
}

\author{
X Mara Chen* \\ Department of Geography \& Geosciences, Salisbury University, USA
}

Submission: August 12, 2018; Published: August 23, 2018

*Corresponding author: X Mara Chen, Department of Geography \& Geosciences, Salisbury University, USA, Email: MXCHEN@salisbury.edu

\section{Short Communication}

Human capital is undoubtedly critical and essential for any civilization. Its prime value is warranted by quality education, sustainable good health care, and the freedom to pursue happiness, independent of demographic profile. Physical and human capital are clear determinants of economic growth [1]. It takes constant and consistent effort and collective sound decision-making to accumulate, extract, distribute and utilize human capitalwith the advancements of sciences and technologies, people around the world have gained much better knowledge and understanding regarding the importance of public health. In general, people in well- developed nations have obtained a better standard of living and enjoyed a much healthier and longer lifespan.

Still, the fast developments have also brought about unprecedented polarity in living standards, emerging new diseases, traumatic brain injuries, drug \& substance abuse and addictions, adverse environmental impacts, and associated societal stress. These tremendous burdens compound the demands for facing new challenges in public health care, from finding cures for many new diseases to ensuring general accessibility of good health care.

\section{Public Ownerships}

Public health needs the cohesive tiers of public ownership, collective effort and enforceable ways of providing and supporting a healthy nation. Public ownership would consist of a multi-tiering system to create a, more-or-less, gently rolling health-care landscape across the nation for burden sharing and enhanced access of health care. The goal is to ensure no major displacements of people for the sake of seeking better healthcare and no big chasms for less fortunate people who are left behind without mobility and adequate access for fundamental care. Tens of millions of people have a mental illness and families experience the burden of suffering from untreated mental illness and addictions [2]. Yet, government de-funding and de- authorization are gutting many traditional public health functions, and the spread of many preventable diseases is on the rise [3-5]. Local, state/city and national governments need to work together to gradually achieve a broader coverage of good health care, including national health database sharing, fundamental disease screening, preventative care, and easy access to new treatments of major urgent health problems. Data sharing and pro-active education and screening measures would help prevent major health problems from becoming epidemic, chronic, and lasting economic burdens, such as obesity, substance and drug addiction, brain injuries and mental illnesses, and epidemic infectious diseases.The U.S. is undoubtedly a global superpower, and yet it ranks 37 in health outcomes [3]. The public health problems we face have historic reasons. It is futile to point fingers backward at who failed us, but more productive to take small steps forward to create a better system.

Quality education and sound public health care should be an essential part of constitutional rights for the people. Some remarkable scientific accomplishments have been achieved in understanding of physical environment, such as air, water, land, and its ecological interconnections with human health. However, more work needs to be done about public health. For sure, better mental and physical health of people are integral to good human capital.The large polarity and disparity in public health would depreciate overall human capitals, the overarching purpose of living and humanity. Consequently, poor healthcare burdens most ordinary patients and families and destabilizes social stability. Eventually, the effectiveness of government will take a lot more resources and public confidence to reinforce and sustain.

\section{Private Operations}

Adam Smith's Invisible Hand theory holds strong and true in all sectors, especially in the socioeconomic- centric public health area.Democratic government structure promotes human ingenuity and efficient faircompetitiveness in doing business. It goes together with capitalistic economic operations. The 
complexity of public health requires a web of insurance, pharmacy, medical industries, research institutions, as well as law and government agencies. As for how to coordinate and collaborate these entities together need good work from private industries, there is an important role for private sector to do the complicated handshakes among various sectors. The desirable outcome is to carry out and to ensure a continuous and cohesive public health care system. The private sector is also pivotal in supporting and providing technologically-enhanced data sharing and individually-tailored health care delivery.

\section{Individual Responsibilities}

Irresponsibly exercised freedom leads to chaos or unattainable/unaffordable/unenforceable liberty. James Lovelock's scientific Gaia Hypothesis presented visionary views on both the importance of treating earth as an organism and people's respect for the interconnectedness of our health and earth's environment health.

At the individual level, the immediate environment is oneself and one's surroundings. Individual persons need to take on the primary duty for their own and their young children's health. Individual's attitude toward health and philosophic approach governs one's value system and lifestyle.First, human body is an intricate complex system, powered by food energy. The U.S. is fortunate to have such a diverse population with rich heritages, and different cultures have their strengths in preparing and serving food. It is good to consciously consume what is needed, preserving earth resources and optimizing their uses.Second, habit-forming efforts are critical in maintaining an active lifestyle. Staying active and fit promotes mental health. It is estimated that one in 10 children suffer from serious emotional and mental disorders, and one in 17 adults lives with a serious mental illness (The National Household Survey on Drug Abuse Report, 2010)Third, education is key to becoming an informed consumer and building a healthy lifestyle.Finally, social and natural environmental connection is an integral part of happy living. Living a high quality socially-connected life is associated with a decrease in mortality and a range of disease morbidities [4].

\section{Summary}

The burden of healthcare and the potential of human capital and economic developments are intertwined. It is imperative to have targeted focus and a strategic approach to preventing major public health problems.Different levels of government need to take ownership of public health to provide quality and accessible health care initiatives: for example, putting universal, fundamental preventative care in place for children; developing and enhancing existing mental health and intellectual development programs for youth; rewarding healthy adults who take self-motivated active drug-free lifestyle; and providing elderly people with a venue for shared activities, focusing on quality social connections, beyond fundamental healthcare. The public health system needs the coordinated synergy of public ownership and regulation, private sector execution, and individual accountability to provide high quality, accessible health care for everyone.

\section{Refernces}

1. BenDavid, Nissim (2009) Economic growth and its effect on public health. International Journal of Social Economics, Bradford 36(3): 252-273.

2. KesslerRC, Demlet O, Frank RG, Olfson M, Pincus HA,et al. (2005) Prevalence and treatment of mental disorders, 1990-2003. New England Journal of Medicine 352(24): 2515-2523.

3. Hanrahan NP, Stuart GW, Delaney KR, Wilson C (2013) Mental health is an urgent public health concern. Nursing Outlook 61: 185-186.

4. HoltLunstad, J Robles TF,Sbrra DA (2017) Advancing social connection as a public health priority in the United States. American Psychologist72(6): 517-530.

5. Hodge JrJG(2018) Constitutional Cohesion and Public Health Part II. The Journal of Law, Medicine \& Ethics 46: 185-188.
Your next submission with Juniper Publishers will reach you the below assets

- Quality Editorial service

- Swift Peer Review

- Reprints availability

- E-prints Service

- Manuscript Podcast for convenient understanding

- Global attainment for your research

- Manuscript accessibility in different formats

( Pdf, E-pub, Full Text, Audio)

- Unceasing customer service

Track the below URL for one-step submission https://juniperpublishers.com/online-submission.php 